\title{
Application and Research of Soil Mixing Wall
}

\author{
Runjie Gu* \\ College of Science \& Technology, Ningbo University, Ningbo 315300, Zhejiang Province, China. E-mail: \\ gurj1999@qq.com
}

Abstract: Soil Mixing Wall can meet the needs of foundation pit support structures in various projects. Compared with other supporting structures, it has the advantages of good permeability resistance, short construction period, and less impact on the surrounding environment. It is a foundation pit supporting structure with great development potential ${ }^{[1]}$.

Keywords: Soil Mixing Wall; Underground Engineering; Construction Technology

\section{Introduction}

Soil Mixing Wall (SMW) is a composite retaining wall water-cutting structure formed by inserting $\mathrm{H}$-shaped steel into continuously sleeved triaxial cement-soil mixing piles. The steel-cement-soil mixing wall is subjected to lateral water and earth pressure by the H-shaped steel, and the cement-soil pile is used as a water cut-off curtain. After the foundation pit project is completed, the H-shaped steel can be pulled out and recycled for reuse. Compared with supporting structures such as diaphragm walls, bored piles and water-stop piles, this supporting structure has the characteristics of economy, short construction period, and environmental protection. The SMW construction method came out in Japan and was later introduced by China. It is currently mainly used It is under maintenance of deep foundation pits in soft soils along the southeast coast of China and is gradually being promoted inland ${ }^{[2]}$.

\section{Construction technology}

\subsection{Profile positioning, guide trench excava- tion}

It is important to preliminarily determine the posi- tion of the section steel and make corresponding marks and remove underground obstacles and excavate guide trenches along the direction of the foundation pit.

\subsection{Mixer in place}

Workers operating the drill and mixer should follow the previously marked section steel position and control the movement of the SMW mixer frame to ensure that the central axis of the drill hole is consistent with the predetermined position.

\subsection{Grouting and mixing}

The grouting material is fine sand that is mostly used in bentonite and high-efficiency alkaline water agent. During the construction process, the accuracy control of the verticality of the pile and the distance between the center of the pile is required. When mixing, it is necessary to repeat the mixing and sinking and lifting and reserve a part of the cement mortar to be poured in during the second mixing and lifting.

\subsection{Place section steel}

After the cement soil is mixed and before the cement soil hardens, the section steel needs to be inserted

This is an open-access article distributed under the terms of the Creative Commons Attribution Non-Commercial License (http://creativecommons.org/licenses/by-nc/4.0/), which permits unrestricted non-commercial use, distribution, and reproduction in any medium, provided the original work is properly cited. 
into the cement soil.

\subsection{Section steel recycling}

After the foundation pit is stable and the enclosure structure has completed its use function, the section steel can be pulled out. The blocks are planned to be pulled out of section steel and determine the order. A vibrating pile puller will be used to clamp the top of the section steel to vibrate until the section steel is separated and separated from the mixing pile, then lift it up while vibrating, and finally pull out the section stee ${ }^{[3]}$.

\subsection{Waste soil transported out}

It is necessary to lean the remaining cement mortar in all pipelines, the waste on the mixing head and the waste soil in the guide ditch, tidy the site, and transport the waste soil out of the construction site.

\section{Project case}

\subsection{Engineering situation}

The first phase of the Nanjing Metro North-South Line project covers 16.84 kilometers. Since the start of the project, the SMW construction method was used to make the enclosure structure of the foundation pit at Zhongsheng Station. The depth of the foundation pit is $14 \mathrm{~m}$, the length is $180 \mathrm{~m}$, and the width is $17-27 \mathrm{~m}$. From top to bottom, the local soil layer consists of artificial fill silty, mucky silty clay and silty clay layer. The bottom plate is located on the mucky silty clay, the silty clay layer, the water content of the mucky silty clay is $\mathrm{w}=42.1 \%$, and the foundation bearing capacity is 70 Mpa. Use triaxial cement-soil mixing piles with a diameter of $0.85 \mathrm{~m}$ and an interval of $0.6 \mathrm{~m}$. H-shaped steel adopts HM700×300, and the insertion form is two-to-one, and the insertion ratio is about 0.78 . The calculated maximum horizontal displacement of the foundation pit is $22.1 \mathrm{~mm}$, and the measured displacement is $24.5 \mathrm{~mm}$. After the completion of the construction, the maximum cumulative value of the ground and building settlement changes measured is $16.34 \mathrm{~mm}$.

\subsection{Key technical issues in engineering}

The Nanjing subway project is a two-story underground or three-story underground structure. The excavation depth of the foundation pit reaches $14 \mathrm{~m}$, and the excavation depth is deeper ${ }^{[4]}$. The excavation area of the deep foundation pit is located in the silty clay layer. In addition, the water content in the soil layer is relatively high, and the soil quality changes from a soft plastic state to a plastic state. Therefore, in the soft soil deep foundation pit, the SMW construction method support structure must deal with the problems caused by the soft soil deep foundation pit excavation ${ }^{[5]}$.

In order to solve the problem in the project, the overall finite element calculation and comparison of the wall deformation are used to analyze and verify the combined stiffness ${ }^{[6]}$. And during the construction process, select typical parts at each site for construction inspection and structural stress testing ${ }^{[7]}$.

\subsection{Project summary}

The successful practice of the project has verified that the water resistance and force strength of the SMW construction method can meet the actual construction requirements. And the actual deformation of the foundation pit after completion is not much different from the design value, and there is no obvious shear failure of the cement soil. The recovery rate of H-beam has reached more than $95 \%$.

\section{Advantage}

\subsection{Little impact on the surrounding envi- ronment}

SMW construction method is a combined structure of cement-soil mixing pile and core material. Compared with the traditional sinking pipe piles and underground continuous walls, which require grooving and drilling, it will cause collapse and even settlement of the ground and surrounding buildings. The SMW method is to use a multi-shaft mixer to mix sand and grout on the spot, without grooving or drilling, which can greatly reduce the harm to the surrounding environment.

\subsection{Wide range of applications}

The SMW construction method can meet the requirements for use in different soil layers such as cohesive soil, silty soil, sand, and gravel soil. If combined with the pre-drilling process, it can also be used in harder soil layers and weathered rock layers.

\subsection{High resistance to both infiltration}

The SMW method requires repeated sinking and 
lifting at a constant speed during the mixing process, so that the cement mortar is fully mixed and evenly mixed. And the use of multi-axis drilling mixer construction, so that the piles are almost seamlessly overlapped and the permeability coefficient of the finished cement-soil is very small, thereby ensuring the permeability of the cement-soil mixing pile.

\subsection{Short construction period, low cost, en- vironmental protection}

The SMW construction method has a short construction period, compared with other foundation pit enclosure structures such as underground diaphragm walls and sunken pipe cast-in-place piles. The SMW construction method is simple to construct, easy to operate, and the construction period can be greatly reduced.

The selection of SMW construction method to complete the foundation pit supporting structure does not require additional water-proof curtains, and the recycling and reuse of section steel can obtain huge advantages that can not be compared with underground continuous walls and sunken pipe cast-in-place piles.

The guide trench excavated by the SMW construction method leads to a small amount of waste soil generated during the construction to avoid pollution. Moreover, the recycling of section steel can save steel and reduce the consumption of steel resources.

\section{Development status and research direction}

The SMW method has been developed by leaps and bounds since its inception in Japan. Compared with other enclosure structures, SMW construction method has the advantages of environmental protection, high economic efficiency, and good permeability resistance. It can be widely used in the construction of underground construction foundation pits, underground dams, and submarine wall construction.

Although the support structure of SMW construction method is simple, the stress mechanism of steel-cement-soil composite material is very complicated. The interaction between section steel and cement-soil, considering the composite strength of the composite structure from the perspective of composite material mechanics, can obtain a more reasonable explanation, correctly calculate the internal force and displacement of the structure, and ensure the rationality and safety of the project $^{[8]}$.

For the application of SMW method in the future, there are still many directions worth studying:

(1) According to the combined structural rigidity of section steel and cement-soil, how to maximize the benefits of cement-soil rigidity on the basis of ensuring safety and stability ${ }^{[9]}$.

(2) Through the establishment of the H-shaped steel pull-out model, it can be considered how to reduce the friction between the steel and the cement soil. The deformation of the retaining wall during the excavation of the foundation pit will cause the steel to be deformed to facilitate the $\mathrm{H}$-shaped steel pull-out work ${ }^{[10]}$.

(3) The application of SMW method in the construction of urban deep foundation pits.

\section{Conclusion}

With the development of society and the needs of urbanization. People are developing deeper and deeper underground space in cities and expanding in scale, and there are new requirements for the enclosure structure of underground foundation pit excavation. The SMW method has achieved good results since its first application in Shanghai, and has subsequently been widely used in China. The successful application of the SMW method in the construction of the Nanjing Metro fully reflects its wide range of applications, and the project has a small impact on the surrounding environment. It also provides valuable experience for the Chinese SMW method in the construction of underground projects. Compared with the traditional foundation pit supporting structure, SMW construction method has many advantages, these advantages enable SMW construction method to be popularized and applied.

\section{References}

1. Lu C. Brief introduction of SMW pile construction technology (in Chinese). Sichuan Building Materials 2018; 44(12): 157-158.

2. Gu S, Shi J, Liu J. Research progress of SMW method (in Chinese). Prospecting Engineering (Rock and Soil Drilling Engineering) 2006; (8): 4-7.

3. Zhang G, Xu Y, Fu D. Experimental study and application of SMW industrial section steel drawing (in Chinese). Journal of Rock Mechanics and Engineering 2002; 21(3): 444-448.

4. Zeng D, Zhu Y. Application of SMW method in 
foundation pit support of Zhujiang Road Station of Nanjing Metro (in Chinese). Municipal Engineering Technology 2006; (5): 321-322+348.

5. Sheng Y. SMW enclosure structure is used to study the deformation law of deep foundation pit in subway station (in Chinese). Nanjing Forestry University; 2009.

6. Xu Y. Research on the key technical difficulties in SMW design and construction (in Chinese). Xuzhou Institute of Technology 2007; (2): 37-42.

7. Zhou S, Liu J, Pan R, et al. Field test and analysis of the new SMW method for foundation pit enclosure (in Chinese). Chinese Journal of Geotechnical En- gineering 2001; (6): 692-695.

8. Zhang P, Liu R. Application of SMW method in deep foundation pit engineering (in Chinese). Chinese Journal of Rock Mechanics and Engineering 2000; (S1): 1104-1107.

9. Gu S, Shi J. Simulation test and working mechanism analysis of SMW method in deep foundation pit (in Chinese). Rock and Soil Mechanics 2008; (4): 11211126.

10. Liu X. Design theory and calculation method of SMW method (in Chinese). Nanjing University of Technology; 2004. 